ARTICLE

https://doi.org/10.1038/s41467-019-12378-0

\title{
Surface-kinetics mediated mesoporous multipods for enhanced bacterial adhesion and inhibition
}

Tiancong Zhao ${ }^{1}$, Liang Chen ${ }^{1}$, Peiyuan Wang ${ }^{1}$, Benhao Li ${ }^{1}$, Runfeng Lin ${ }^{1}$, Areej Abdulkareem Al-Khalaf², Wael N. Hozzein (10 ${ }^{3,4}$, Fan Zhang (10) ${ }^{1}$, Xiaomin Li (i) ${ }^{1 \star} \&$ Dongyuan Zhao (D) ${ }^{1 \star}$

Despite the importance of nanoparticle's multipods topology in multivalent-interactions enhanced nano-bio interactions, the precise manipulation of multipods surface topological structures is still a great challenge. Herein, the surface-kinetics mediated multi-site nucleation strategy is demonstrated for the fabrication of mesoporous multipods with precisely tunable surface topological structures. Tribulus-like tetra-pods $\mathrm{Fe}_{3} \mathrm{O}_{4} @ \mathrm{SiO}_{2} @ \mathrm{RF} \& \mathrm{PMOs}$ $(\mathrm{RF}=$ resorcinol-formaldehyde resin, $\mathrm{PMO}=$ periodic mesoporous organosilica) nanocomposites have successfully been fabricated with a centering core@shell $\mathrm{Fe}_{3} \mathrm{O}_{4} @ \mathrm{SiO}_{2} @ \mathrm{RF}$ nanoparticle, and four surrounding PMO nanocubes as pods. By manipulating the number of nucleation sites through mediating surface kinetics, a series of multipods mesoporous nanocomposites with precisely controllable surface topological structures are formed, including Janus with only one pod, nearly plane distributed dual-pods and tri-pods, threedimensional tetrahedral structured tetra-pods, etc. The multipods topology endows the mesoporous nanocomposites enhanced bacteria adhesion ability. Particularly, the tribuluslike tetra-pods mesoporous nanoparticles show $\sim 100 \%$ bacteria segregation and long-term inhibition over $90 \%$ after antibiotic loading.

\footnotetext{
${ }^{1}$ Department of Chemistry and Laboratory of Advanced Materials, State Key Laboratory of Molecular Engineering of Polymers, Collaborative Innovation Center of Chemistry for Energy Materials (2011-iChEM), Fudan University, Shanghai 200433, PR China. ${ }^{2}$ Biology Department, College of Science, Princess Nourah Bint Abdulrahman University, Riyadh, Saudi Arabia. ${ }^{3}$ Bioproducts Research Chair, Zoology Department, College of Science, King Saud University, Riyadh 11451, Saudi Arabia. ${ }^{4}$ Botany and Microbiology Department, Faculty of Science, Beni-Suef University, Beni-Suef, Egypt.

*email: lixm@fudan.edu.cn; dyzhao@fudan.edu.cn
} 
T here are many characters worth learning from intriguing natural creations for developing functional materials with versatile applications ${ }^{1-5}$, especially the surface topological structure enhanced interfacial interactions in natural world. For example, tribulus seeds usually have a few sharp rigid burs on the surface, i.e., multipods shape, ensuring that the seeds can be easily attached onto the fur of animals for spreading ${ }^{6}$. Viruses can invade cell membranes through their multiple pod-like spikes ${ }^{7-9}$. Similarly, it has been widely recognized that the strong interaction between nanoparticles and bio-hosts is crucial for intracellular drug delivery, bacterial inhibition, and so on ${ }^{10-12}$, which is quite related to the surface topology induced multivalent nanobio interactions ${ }^{13-15}$. Like the tribulus seeds and viruses, the multipods surface structure can provide nanomaterials with multivalent interactions toward biological interfaces, thus achieving higher binding strength, enhanced adherence and penetration into biological hosts ${ }^{16-18}$. However, it is still a great challenge to fabricate such multipods structured nanoparticles with precisely controlled surface topological structures. Furthermore, most of the reported multipods nanomaterials are based on dense crystals ${ }^{19-23}$, polymers ${ }^{24,25}$, etc., which cannot provide enough storage space for functional guest molecule loading, restricting the further practical applications of the nanomaterials with multipods surface topological structures.

To obtain multipods nanoparticles with both precisely controllable surface topological structure and large storage space for functional molecules loading, the controllable multi-site nucleation of porous pods during nanoparticles' surface manufacturing plays a crucial role 26,27 . Recently, the anisotropic island nucleation and growth strategy have been developed for the fabrication of various intriguing asymmetric mesoporous nanomaterials, such as Janus nanoparticles ${ }^{28-30}$, eccentric single-hole nanorattles ${ }^{31}$, onedimensional (1D) diblock and triblock nanocomposites ${ }^{32}$, etc. However, the number of nucleation sites for the mesoporous pods assembly has been restricted to one for the fabrication of asymmetric dimer structure, and the island nucleation and growth of these pods are randomly distributed. It is still a great challenge to precisely control the number and distribution of nucleation sites for the fabrication of multipods mesoporous nanoparticles with controllable surface topological structures.

Herein, the surface-kinetic mediated multi-site nucleation strategy is demonstrated to precisely control the nucleation number of periodic mesoporous organosilicas (PMOs) on the surface of resorcinol-formaldehyde resin (RF). The tetra-pods $\mathrm{Fe}_{3} \mathrm{O}_{4} @ \mathrm{SiO}_{2} @ \mathrm{RF} \& \mathrm{PMOs}$ ( $\mathrm{RF}=$ resorcinol-formaldehyde resin) mesoporous nanocomposites have been fabricated (Fig. 1). The multipods are made up of one $\mathrm{Fe}_{3} \mathrm{O}_{4} @ \mathrm{SiO}_{2} @ \mathrm{RF}$ core@shell nanosphere with a diameter of $260 \mathrm{~nm}$ as a center, and four 150-nm PMO cubes as pods on the surface. By regulating the surface nucleation kinetic of PMO multi-site growth on polymeric RF shell, a family of multipods structured mesoporous nanocomposites with controllable surface topological structures are obtained (Janus nanostructure with only one PMO pod on RF surface, dual-pods and tri-pods with nearly plane distribution, three dimensional tetrahedral structured tetra-pods, etc.). The multipods topology endows the obtained mesoporous nanocomposites high bacteria adhesion efficiency through multivalent interactions. Due to the multipods structure enhanced bio-nano interactions and high surface area $\left(\sim 584 \mathrm{~m}^{2} \mathrm{~g}^{-1}\right)$ for antibiotic loading, the tetra-pods nanoparticles perform nearly $100 \%$ bacteria segregation and over $90 \%$ long-term inhibition abilities.

\section{Results}

Tribulus-like mesoporous tetra-pods $\mathrm{Fe}_{3} \mathrm{O}_{4} @ \mathrm{SiO}_{2} @ \mathrm{RF} \& \mathrm{PMOs}$. Superparamagnetic $\mathrm{Fe}_{3} \mathrm{O}_{4}$ nanoparticles are prepared through a solvothermal method, which are successively coated with polymeric $\mathrm{SiO}_{2}$ and $\mathrm{RF}$ through the sol-gel process, forming uniform $\mathrm{Fe}_{3} \mathrm{O}_{4} @ \mathrm{SiO}_{2} @ \mathrm{RF}$ core@shell structured nanospheres (Fig. 1a). Then, the mesoporous tetra-pods are fabricated through the surface-kinetics mediated multi-site nucleation and growth of PMOs on the surface of the $\mathrm{Fe}_{3} \mathrm{O}_{4} @ \mathrm{SiO}_{2} @ \mathrm{RF}$ nanoparticles: each $\mathrm{Fe}_{3} \mathrm{O}_{4} @ \mathrm{SiO}_{2} @ \mathrm{RF}$ core particle is surrounded by four separated PMO pods, forming a tribulus like tetrahedral structured tetra-pods $\mathrm{Fe}_{3} \mathrm{O}_{4} @ \mathrm{SiO}_{2} @ \mathrm{RF} \& \mathrm{PMOs}$ mesoporous nanocomposite (denoted as T-RF\&PMOs). As shown in transmission electron microscopy (TEM) images (Fig. 1b, and Supplementary Fig. 1), the magnetite $\mathrm{Fe}_{3} \mathrm{O}_{4}$ nanoparticles synthesized through the solvothermal method at $200^{\circ} \mathrm{C}$ have a diameter of $100 \mathrm{~nm}$, the thicknesses for the coated $\mathrm{SiO}_{2}$ and RF layers are measured to be both $40 \mathrm{~nm}$, together forming the $\mathrm{Fe}_{3} \mathrm{O}_{4} @ \mathrm{SiO}_{2} @ \mathrm{RF}$ core@shell structured nanospheres with $260 \mathrm{~nm}$ in diameter. For the T-RF\&PMOs nanoparticles, TEM and scanning electron microscopy (SEM) images clearly demonstrate the 3D tetra-pods topological structure (Fig. 1b-d \& Supplementary Fig. 2), and that the PMO nanocubes have similar size of $\sim 150 \mathrm{~nm}$ in side length (Supplementary Fig. 3). The four PMO nanocubes are uniformly anchored on the surface of one $\mathrm{Fe}_{3} \mathrm{O}_{4} @ \mathrm{SiO}_{2} @ \mathrm{RF}$ nanosphere, and their relative position constitutes a nearly regular tetrahedron topology (Supplementary Fig. 4). Different elements in one $\mathrm{Fe}_{3} \mathrm{O}_{4} @ \mathrm{SiO}_{2} @ \mathrm{RF}$ nanosphere (iron, carbon) and four discrete PMO pods (silicon) can be clearly identified by the energy dispersive spectrometer (EDS) mapping (Fig. 1e), further demonstrating the tetra-pods topology. Three scattering peaks at q-value of $1.35,1.51$, and $1.65 \mathrm{~nm}^{-1}$ are observed in the small-angle X-ray scattering patterns of the T-RF\&PMOs nanoparticles, which correspond to the 200,210, and 211 reflections of the cubic mesostructure ( $\operatorname{Pm} \overline{3} \mathrm{n}$ ) (Supplementary Fig. 5). This result clearly indicates the ordered cubic mesostructure of the PMO cube pods, which is consistent with the high-resolution TEM (HRTEM) images of the PMO pods along the [210] and [001] zone axis (Fig. 1f, g). It's worth mentioning that the surface of the initial RF nanospheres without the deposition of PMO cubes is also covered by a very thin layer of organosilicas. The main difference between such layer and PMO cubes is that the thin layer of organosilica does not have ordered mesostructure. Nitrogen sorption isotherms of the obtained mesoporous T-RF\&PMOs nanoparticles exhibit representative type-IV curve with a rapid increase of adsorption volume at a relative pressure of $0.2-0.4$, indicating uniformity of the mesopores in the nanocomposites. The Brunauer -Emmett-Teller (BET) surface area is calculated to be as high as $584 \mathrm{~m}^{2} \mathrm{~g}^{-1}$ (Fig. 1h). From the pore size distribution curve obtained by the Barrett-Joyner-Halenda (BJH) method, the mesoporous Janus nanocomposites exhibit a narrow mesopore size distribution with an average diameter of $\sim 2.6 \mathrm{~nm}$, which is mainly derived from the ordered mesopores of the PMO pods. With the presence of the magnetic $\mathrm{Fe}_{3} \mathrm{O}_{4}$ cores, the T-RF\&PMOs multipods nanoparticles exhibit superparamagnetic properties with a saturation magnetization value of $20 \mathrm{emu} \mathrm{g}^{-1}$, which is enough for magnetic induced separations in the practical applications (Supplementary Fig. 6). The multipods nanoparticles are well dispersed in Luria-Bertani (LB) solution over $12 \mathrm{~h}$, demonstrating a good stability (Supplementary Fig. 7). The stability of the multipods nanoparticles in LB, phosphate buffer saline (PBS), acid and basic solutions, etc. are also evaluated by dynamic light scattering (DLS). The results show that the average diameters of the nanoparticles remain nearly constant in different solutions over a long period of times, indicating no aggregation of the nanoparticles in the solutions (Supplementary Fig. 8). Altogether, the multipods 
a

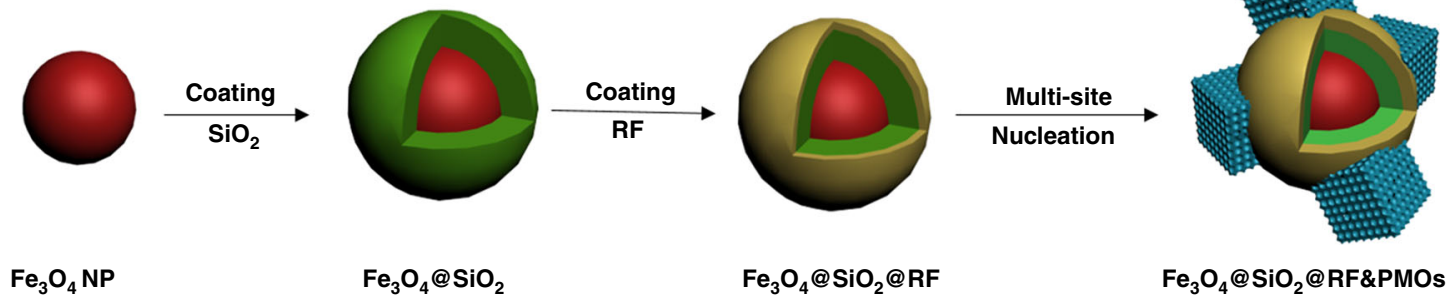

b

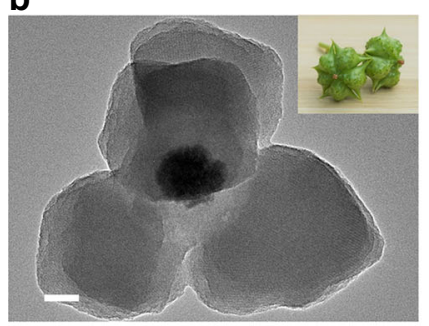

f

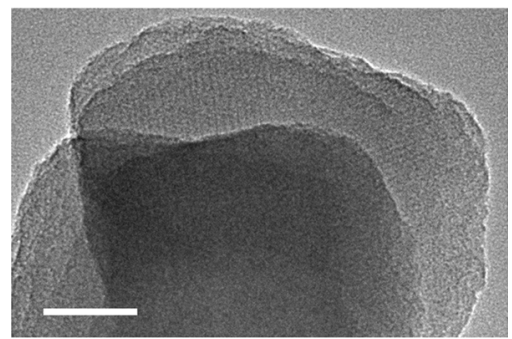

C

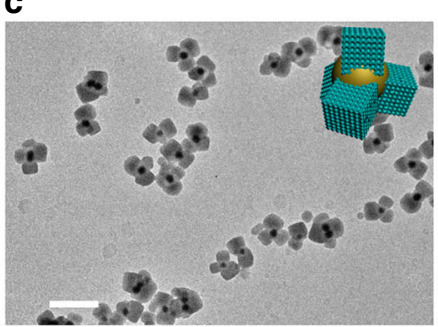

g

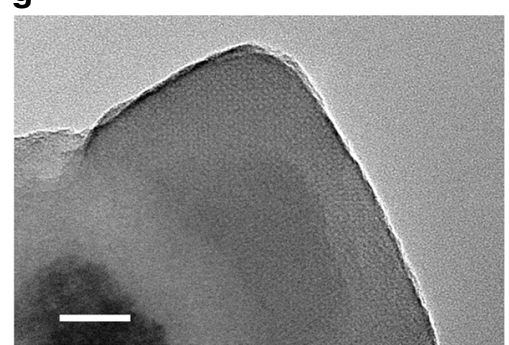

d

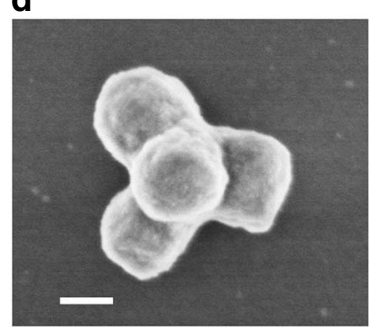

e



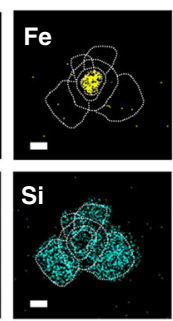

h



Fig. 1 Synthesis and characterization of tribulus-like tetra-pods nanocomposites. a Fabrication process scheme of the tetra-pods Fe $\mathrm{O}_{4} @ \mathrm{SiO}_{2} @ \mathrm{RF} \& \mathrm{PMOs}$ nanoparticles based on the surface-kinetic mediated multi-site nucleation strategy. b, c TEM images with different magnifications, d SEM image and e element mapping of the tribulus-like tetra-pods $\mathrm{Fe}_{3} \mathrm{O}_{4} @ \mathrm{SiO}_{2} @ \mathrm{RF} \& \mathrm{PMOs}$ mesoporous nanocomposites. Inset in $\mathbf{b}$ : a digital photo of tribulus seeds; Inset in c: 3D structural model of the tetra-pods $\mathrm{Fe}_{3} \mathrm{O}_{4} @ \mathrm{SiO}_{2} @ R F \& P M O s$ nanoparticles. $\mathbf{f}, \mathbf{g}$ HRTEM images of the typical PMO pods of tetra-pods $\mathrm{Fe}_{3} \mathrm{O}_{4} @ \mathrm{SiO}_{2} @ \mathrm{RF} \& \mathrm{PMOs}$ nanoparticles along $\mathbf{f}$ [210] and $\mathbf{g}$ [001] zone axis. $\mathbf{h}$ The nitrogen sorption isotherms and pore size distribution (inset) of the tetra-pods nanoparticles. Scale bars represent $50 \mathrm{~nm}$ in $\mathbf{b}, \mathbf{f}, \mathbf{g}, 100 \mathrm{~nm}$ in $\mathbf{d}, \mathbf{e}$, and $500 \mathrm{~nm}$ in $\mathbf{c}$. Source data underlying $\mathbf{h}$ are provided as a Source Data file

topology, high surface area and ordered mesostructure endow the T-RF\&PMOs nanoparticles great potentials for applications with enhanced nano-bio interactions.

In stark contrast, the nucleation of cubic PMOs upon the bare $\mathrm{Fe}_{3} \mathrm{O}_{4} @ \mathrm{SiO}_{2}$ nanoparticles leads to the formation of Janus nanostructured $\mathrm{Fe}_{3} \mathrm{O}_{4} @ \mathrm{SiO}_{2} \& \mathrm{PMO}$ with only one $\mathrm{PMO}$ pod (Fig. 2a) ${ }^{28}$. The $\mathrm{Fe}_{3} \mathrm{O}_{4} @ \mathrm{SiO}_{2}$ nanoparticles with a diameter of $\sim 260 \mathrm{~nm}$ are the same size with $\mathrm{Fe}_{3} \mathrm{O}_{4} @ \mathrm{SiO}_{2} @ \mathrm{RF}$ nanoparticles, only without the RF layer coating (all reaction conditions are the same) (Supplementary Fig. 9). It can be seen that the obtained nanoparticles show an obvious asymmetric Janus nanostructure, which are composed by closely connected $\mathrm{Fe}_{3} \mathrm{O}_{4} @ \mathrm{SiO}_{2}$ core@shell nanosphere $(\sim 260 \mathrm{~nm}$ in diameter $)$ and a PMO nanocube $(\sim 250 \mathrm{~nm}$ in edge length). Compared with the PMO pods in the T-RF\&PMOs, the size of the PMO cube in the Janus nanostructured is relatively larger. The cubic mesostructure (space group of $\operatorname{Pm} \overline{3} \mathrm{n}$ ), diameter of the mesopore etc. are maintained and consistent with that in the T-RF\&PMOs. $\mathrm{Fe}_{3} \mathrm{O}_{4} @ \mathrm{RF}$ nanoparticles with diameter of $\sim 260 \mathrm{~nm}$ were also synthesized and used as the substrate for the multi-site nucleation and growth of PMOs. The mesoporous multipods $\mathrm{Fe}_{3} \mathrm{O}_{4} @ \mathrm{RF} \& \mathrm{PMOs}$ can also be synthesized under the same reaction conditions (Supplementary Fig. 10). These results clearly indicate that the surface properties have significant impact on the multi-site nucleation of PMOs, which will be described in the following part.
The controllable surface topological structures. As mentioned above, the Janus/mono-pod and tetra-pods structured nanoparticles can be obtained by the heterogeneous nucleation and growth of PMO nanocubes on the $\mathrm{SiO}_{2}$ and $\mathrm{RF}$ surface, respectively, indicating that the surface properties have significant impact on the multi-site nucleation of PMOs. However, when polyvinyl pyrrolidone (PVP) is used to modify the surface of $\mathrm{Fe}_{3} \mathrm{O}_{4} @ \mathrm{SiO}_{2} @ \mathrm{RF}$ nanoparticles, the surface kinetics for PMOs growth is changed, the multi-site nucleation is suppressed, and the number of the PMO pods is restrained to only one, leading to reinstatement of the Janus $\mathrm{Fe}_{3} \mathrm{O}_{4} @ \mathrm{SiO}_{2} @ \mathrm{RF} \& \mathrm{PMO}$ structures (Fig. 2c, Supplementary Fig. 11). The intermediate surface topological structure with 1-2 cubes grown on each nanoparticle is also obtained with the decreasing amount of PVP on the surface of $\mathrm{Fe}_{3} \mathrm{O}_{4} @ \mathrm{SiO}_{2} @ \mathrm{RF}$ nanoparticles (Supplementary Fig. 12). Other kinds of polymers, such as poly(sodium- $p$-styrenesulfonate) (PSS) also possess such function to suppress multi-site nucleation of PMOs on RF surface (Supplementary Fig. 13). These results clearly indicate that the multi-site nucleation for the formation of the multipods architecture is mainly ascribed to the surface property of the RF outer layer, allowing precise manipulation of the multipods topological structure through particles' surface property manipulation.

To further investigate the effects of surface property on mediation of the multi-site nucleation for the formation of 
a

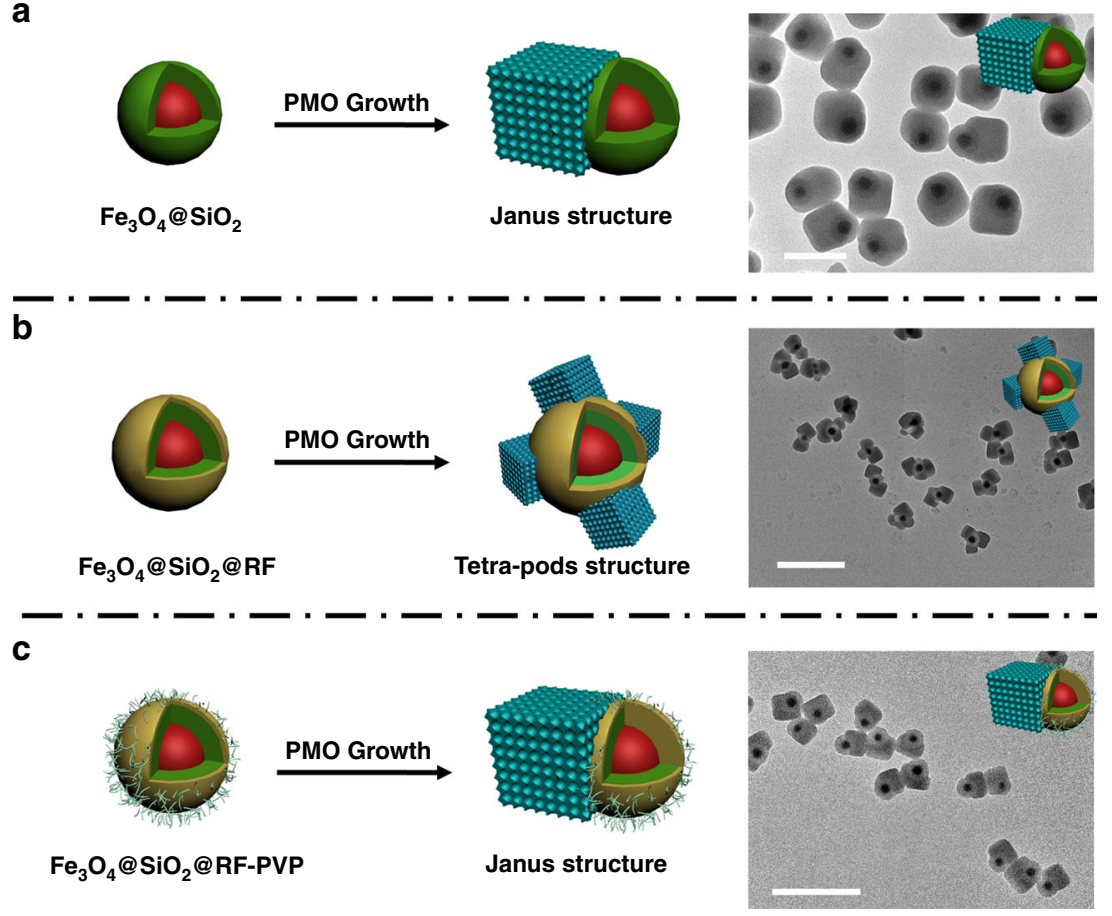

Fig. 2 The growth of PMO cubes on nanoparticles with different surface compositions. a The growth of PMOs on the core@shell Fe $\mathrm{O}_{3} @ \mathrm{SiO}_{2}$ nanospheres and the TEM image of the resultant Janus $\mathrm{Fe}_{3} \mathrm{O}_{4} @ \mathrm{SiO}_{2} \& \mathrm{PMO}$ nanocomposites; b The multi-sites growth of $\mathrm{PMOs}_{\mathrm{O}}$ on the $\mathrm{Fe}_{3} \mathrm{O}_{4} @ \mathrm{SiO}_{2} @ \mathrm{RF}$ nanospheres and the TEM image of the resultant tetra-pods $\mathrm{Fe}_{3} \mathrm{O}_{4} @ \mathrm{SiO}_{2} @ \mathrm{RF} \& \mathrm{PMOs}$ nanocomposites; $\mathbf{c}$ The growth of PMOs on the PVP modified Fe $\mathrm{O}_{4} @ \mathrm{PiO}_{2} @ \mathrm{RF}$ nanospheres and the TEM image of the resultant Janus $\mathrm{Fe}_{3} \mathrm{O}_{4} @ \mathrm{SiO}_{2} @ R F-P V P \& P M O$ nanocomposites. Insets are the 3D structural model of the respective nanocomposites. Scale bars represent $500 \mathrm{~nm}$ in a, and $1 \mu \mathrm{m}$ in $\mathbf{b}, \mathbf{c}$

multipods structures, the surface of the core@shell structured $\mathrm{Fe}_{3} \mathrm{O}_{4} @ \mathrm{SiO}_{2} @ \mathrm{RF}$ nanoparticles is functionalized with phenolic amino (RF-A) or phenolic nitro (RF-N) groups, and the corresponding nanoparticles are denoted as $\mathrm{Fe}_{3} \mathrm{O}_{4} @ \mathrm{SiO}_{2} @ \mathrm{RF}-\mathrm{A}$ and $\mathrm{Fe}_{3} \mathrm{O}_{4} @ \mathrm{SiO}_{2} @ \mathrm{RF}-\mathrm{N}$, respectively (Supplementary Fig. 14). After heterogeneous nucleation and growth of PMOs on the nanoparticles, the obtained $\mathrm{Fe}_{3} \mathrm{O}_{4} @ \mathrm{SiO}_{2} @ \mathrm{RF}-\mathrm{A} \& \mathrm{PMOs}$ multipods nanocomposites with amino groups mainly possess two cubic pods (Fig. 3a), less than that of tribulus-like $\mathrm{Fe}_{3} \mathrm{O}_{4} @$ $\mathrm{SiO}_{2} @ \mathrm{RF} \& \mathrm{PMOs}$ nanoparticles with tetra-pods topology (obtained by the heterogeneous nucleation and growth of PMOs on RF surface with phenolic hydroxyl group) (Fig. 3b). The side length of the cubes are $\sim 260 \mathrm{~nm}$, slightly larger than that of $\mathrm{Fe}_{3} \mathrm{O}_{4} @ \mathrm{SiO}_{2} @ \mathrm{RF} \& \mathrm{PMOs}$ tetra-pods nanocomposites. In most $\mathrm{Fe}_{3} \mathrm{O}_{4} @ \mathrm{SiO}_{2} @ \mathrm{RF}-\mathrm{A} \& \mathrm{PMO}$ dual-pods nanocomposites, the relative position among the two PMO cubes and $\mathrm{Fe}_{3} \mathrm{O}_{4} @ \mathrm{SiO}_{2} @ \mathrm{RF}-\mathrm{A}$ have a plane obtuse triangle structure or nearly linear alinement, indicating that the heterogeneous nucleation of PMOs on the polymeric RF-A surface tends to spontaneously keep away from each other to minimize the system energy. In contrast, the mesoporous $\mathrm{Fe}_{3} \mathrm{O}_{4} @ \mathrm{SiO}_{2} @ \mathrm{RF}-\mathrm{N} \& \mathrm{PMOs}$ nanocomposites with more than four PMO pods (6-8 cubes according to TEM images) can be obtained after heterogeneous nucleation and growth of PMOs on the RF-N surface with phenolic nitro functional groups (Fig. 3c). The PMO pods possess homogeneous size of $\sim 80 \mathrm{~nm}$, and are evenly distributed on the surface of the core-shell $\mathrm{Fe}_{3} \mathrm{O}_{4} @ \mathrm{SiO}_{2} @ \mathrm{RF}-\mathrm{N}$ nanoparticles. These results further imply that the localized surface property of the nanoparticles has great influence on the heterogeneous multi-sites nucleation of PMOs.

Theoretically, the number of nucleation sites is positively correlated with the surface area. To verify this assumption, core@shell $\mathrm{Fe}_{3} \mathrm{O}_{4} @ \mathrm{SiO}_{2} @ \mathrm{RF}$ nanoparticles with the same surface property but different diameters are used for the heterogeneous multi-sites nucleation and growth of PMOs. Uniform tetra-pods topologies can be formed based on $\mathrm{Fe}_{3} \mathrm{O}_{4} @ \mathrm{SiO}_{2} @ \mathrm{RF}$ with a large diameter of $260 \mathrm{~nm}$ (Fig. 1). In contrast, tri-pods (Fig. 4a), bi-pods (Fig. 4b) and mono-pod (Fig. 4c) structured nanocomposites are obtained when the diameter of $\mathrm{Fe}_{3} \mathrm{O}_{4} @ \mathrm{SiO}_{2} @ \mathrm{RF}$ nanoparticles decrease to 230,200 , and $160 \mathrm{~nm}$, respectively. When the diameter of $\mathrm{Fe}_{3} \mathrm{O}_{4} @ \mathrm{SiO}_{2} @ \mathrm{RF}$ nanoparticles increases to $>300 \mathrm{~nm}$, more complicated multi-pods $(>10)$ nanostructures can be obtained (Supplementary Fig. 15). All the obtained multi-pods nanoparticles are uniform and well dispersed. The $\mathrm{Fe}_{3} \mathrm{O}_{4} @ \mathrm{SiO}_{2} @ \mathrm{RF}$ nanoparticles are considered as an ideal sphere. The outer surface area of nanospheres can be calculated according to the equation $S=\pi d^{2}$ ( $d$ is the diameter of the nanoparticles). The correlation between the number of PMO cubes (nucleation site number) and the surface area per $\mathrm{Fe}_{3} \mathrm{O}_{4} @ \mathrm{SiO}_{2} @ \mathrm{RF}$ nanoparticle is established, showing nearly linear relation (Fig. 4d). The average area for one nucleationsite on the pure RF surface is estimated to be about $6 \times 10^{4} \mathrm{~nm}^{2}$. The linear correlation between the nucleation site number and surface area indicates that the formation of the multiple PMO nucleation sites on RF surface is an even distribution manner, which further induces the most stable and highest symmetric structure for the multipods nanocomposites. It is consistent with the nearly linear alinement for dual-pods nanocomposites and nearly regular tetrahedron structure for the tetra-pods nanocomposites. Beside the number of the PMO cubes, the average side length of the cubes decreased from 300 to $100 \mathrm{~nm}$ as increasing of the number of PMO cubes on the $\mathrm{Fe}_{3} \mathrm{O}_{4} @ \mathrm{SiO}_{2} @ \mathrm{RF}$ surface from 1 to 8 . When the total amount of the silane precursors is constant, the more cubes grown, the smaller the size of each one (Supplementary Fig. 16).

Besides the surface functional group and external surface area, the influence of surface structure (non-porous surface VS mesoporous surface) on the heterogeneous multi-site nucleation 
a

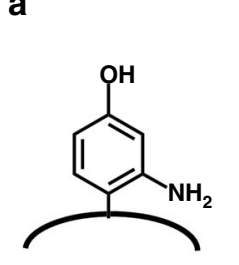

RF-A surface


Fig. 3 The growth of PMO cubes on nanoparticles with different functional groups. a-c The structure of the surface functional groups on $\mathrm{Fe}_{3} \mathrm{O}_{4} @ \mathrm{SiO}_{2} @ \mathrm{RF}$ A, $\mathrm{Fe}_{3} \mathrm{O}_{4} @ \mathrm{SiO}_{2} @ \mathrm{RF}$, and $\mathrm{Fe}_{3} \mathrm{O}_{4} @ \mathrm{SiO}_{2} @ \mathrm{RF}-\mathrm{N}$ nanoparticles and the corresponding TEM images with different magnifications of the obtained multipods nanocomposites: a The growth of PMO cubes on core@shell Fe $\mathrm{O}_{4} @ \mathrm{SiO}_{2} @ R F-A$ nanoparticles with phenolic amino surface functional groups and TEM images with different magnifications of the obtained dual-pods $\mathrm{Fe}_{3} \mathrm{O}_{4} @ \mathrm{SiO}_{2} @ \mathrm{RF}-\mathrm{A} \& \mathrm{PMOs}$ nanocomposites; $\mathbf{b}$ The growth of PMO cubes on the core@shell $\mathrm{Fe}_{3} \mathrm{O}_{4} @ \mathrm{SiO}_{2} @ \mathrm{RF}$ nanoparticles with phenolic hydroxyl surface functional groups and the TEM images with different magnifications of the obtained tetra-pods $\mathrm{Fe}_{3} \mathrm{O}_{4} @ \mathrm{SiO}_{2} @ \mathrm{RF} \& \mathrm{PMOs}$ nanocomposites; c The growth of PMO cubes on the surface of $\mathrm{Fe}_{3} \mathrm{O}_{4} @ \mathrm{SiO}_{2} @ \mathrm{RF}-\mathrm{N}$ nanoparticles with phenolic nitro functional groups and TEM images with different magnifications of the obtained multipods Fe $\mathrm{O}_{4} @ \mathrm{SiO}_{2} @ \mathrm{RF}-\mathrm{A}_{\mathrm{S}} \mathrm{PMOs}$ nanocomposites. Insets are the 3D structural model of the respective nanocomposites. Scale bars represent $500 \mathrm{~nm}$ for images in the middle line and $100 \mathrm{~nm}$ for images in the right line

of PMO on RF surface was also investigated. The $\mathrm{Fe}_{3} \mathrm{O}_{4} @ \mathrm{mRF}$ nanoparticles $(\mathrm{mRF}=$ mesoporous $\mathrm{RF})$ with mesoporous $\mathrm{RF}$ shells are fabricated (Fig. 4e, g) and used for the multi-site nucleation and assembly of PMOs (Fig. $4 \mathrm{f}, \mathrm{h}$ ) on their surface. For the $\mathrm{Fe}_{3} \mathrm{O}_{4} @ \mathrm{mRF}$ nanoparticles with a diameter of $\sim 200 \mathrm{~nm}$, four to six PMO cubes can be grown on each nanoparticles (Fig. 4f), which is more than the nuclei number on the above mentioned non-porous RF surface of the $\mathrm{Fe}_{3} \mathrm{O}_{4} @ \mathrm{SiO}_{2} @ \mathrm{RF}$ nanoparticles (the same particle diameter) (Fig. 4b). When the size of the $\mathrm{Fe}_{3} \mathrm{O}_{4} @ \mathrm{mRF}$ increases to $300 \mathrm{~nm}$, the number of the PMO pods also increases to $>10$ (Fig. $4 \mathrm{~h}$, Supplementary Fig. 17). The increase of nuclei number for the multi-site nucleation of PMO on mesoporous RF surface indicates that the mesopore channels can provide additional active surface area for the multi-site nucleation of PMO, leading to increased pod numbers.

The surface-kinetics mediated multi-site nucleation strategy is universal in manipulating the surface topological structure of various nanomaterials, including $\mathrm{Fe}_{2} \mathrm{O}_{3}$ spindles, $\mathrm{Fe}_{2} \mathrm{O}_{3}$ cubes, graphene oxide (GO) and carbon nanotubes (CNT). The surfaces of these materials are first modified with RF layers (Supplementary Fig. 18), then PMO cubes can be grown through the surfacekinetics mediated multi-site nucleation strategy to form multipods surface topological structures (Supplementary Fig. 19). However, unlike the uniform multi-site nucleation of PMOs on isotropic $\mathrm{Fe}_{3} \mathrm{O}_{4} @ \mathrm{SiO}_{2} @ \mathrm{RF}$ nanospheres, the distribution of the $\mathrm{PMO}$ cubes on the spindles, cubes and nanotubes are not as uniform as the tetra-pods $\mathrm{Fe}_{3} \mathrm{O}_{4} @ \mathrm{SiO}_{2} @ \mathrm{RF} \& \mathrm{PMOs}$ nanoparticles, which can be attributed to the anisotropic morphology of the spindles, cubes and nanotubes. Such general applicability promises the fabrication of multipods nanocomposites with various functions. Furthermore, this surface-kinetics mediated multi-site nucleation strategy can also be utilized for multi-site growth of PMO nanorods with hexagonal mesostructure (space group of p6mm), resulting in multipods morphology with multiple nanorod as pods, indicating that it is generalized to other kinds of mesoporous structures (Supplementary Fig. 20). Altogether, such method exhibits both general applicability as well as precise manipulation, showing a potential in manufacturing nanomaterials' surface topologies.

Enhanced bacterial adhesion and inhibition. Bacterial infection presents a major threat to public health, especially with the increasing level of antimicrobial resistance in recent decades, causing large number of illness and death ${ }^{33,34}$. Present methods for elimination of bacteria all call for strong interactions between materials and bacteria. In analogy of tribulus' adhesion toward animal's skin and fur, it is hypothesized that the fabricated T-RF\&PMOs with multipods topology can also provide enhanced interaction toward bacteria. Escherichia coli (E. coli), a typical Gram-negative strain ${ }^{35,36}$, is used as a model to evaluate the bacterial adhesion ability of T-RF\&PMOs nanoparticles with tetra-pods topological structure. The asymmetric J-RF\&PMO with Janus morphology and spherical core@shell structured $\mathrm{Fe}_{3} \mathrm{O}_{4} @$ $\mathrm{SiO}_{2} @ \mathrm{RF} @ \mathrm{PMO}$ (denoted as RF@PMO) nanoparticles 
a

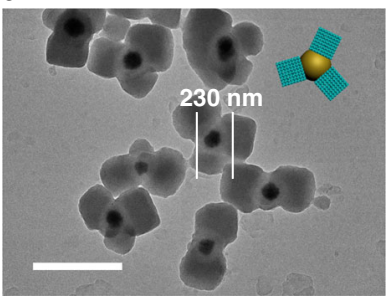

e

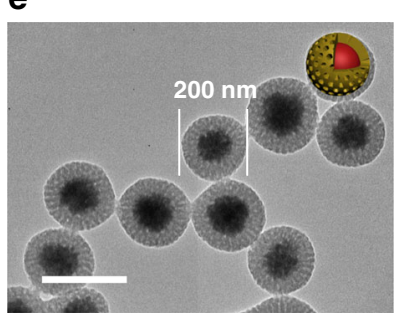

b

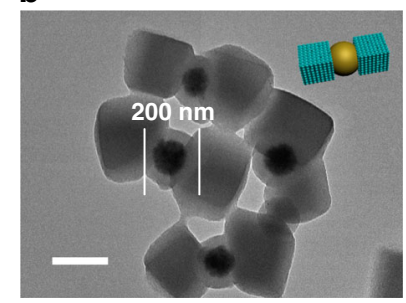

f

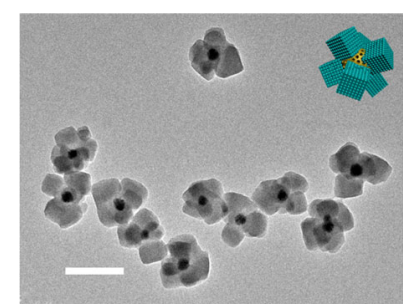

c

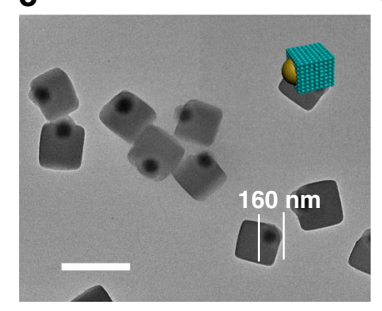

g



d

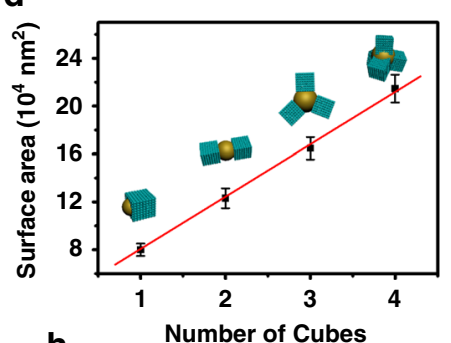

h

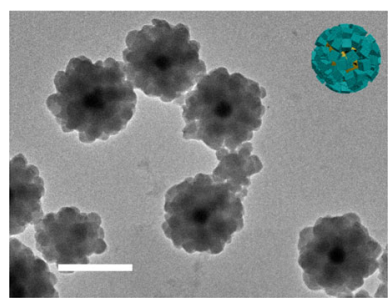

Fig. 4 The growth of PMO cubes on nanoparticles with different outer surface area. a-c TEM images of the multipods Fe $\mathrm{O}_{4} @ \mathrm{SiO}_{2} @ \mathrm{RF} \& \mathrm{PMOs}$ nanocomposites with controllable number of mesoporous PMO cubes by tuning the diameter of $\mathrm{Fe}_{3} \mathrm{O}_{4} @ \mathrm{SiO}_{2} @ \mathrm{RF}$ substrate nanoparticles: $\mathbf{a} 230$ nm, b $200 \mathrm{~nm}$ and $\mathbf{c} 160 \mathrm{~nm}$; d The linear fitting of the number of PMO cubes of the multipods Fe $\mathrm{O}_{3} @ \mathrm{SiO}_{2} @ \mathrm{RF} \& \mathrm{PMOs}$ nanoparticles versus single particle surface area of the initial $\mathrm{Fe}_{3} \mathrm{O}_{4} @ \mathrm{SiO}_{2} @ \mathrm{RF}$ nanoparticles; e-h TEM images of the $\mathrm{Fe}_{3} \mathrm{O}_{4} @$ mRF nanoparticles with different diameters (e, 200 nm; $\mathbf{g}$, 300 $\mathrm{nm}$ ) and the obtained corresponding multipods structured $\mathrm{Fe}_{3} \mathrm{O}_{4} @$ mRF\&PMOs nanoparticles f $\mathbf{f}$. h. Insets are 3D structural models of the multi-pods $\mathrm{Fe}_{3} \mathrm{O}_{4} @ \mathrm{SiO}_{2} @ \mathrm{RF} \& \mathrm{PMOs}$ nanoparticles, Fe $\mathrm{O}_{4} @ m R F$ nanoparticles and multi-pods Fe $\mathrm{O}_{4} @$ mRF\&PMOs nanoparticles. Scale bars represent 200 nm in $\mathbf{b}, \mathbf{e}, \mathbf{g}$ and $500 \mathrm{~nm}$ in $\mathbf{a}, \mathbf{c}, \mathbf{f}, \mathbf{h}$. The bars represent mean \pm s.d. derived from $n=10$ randomly selected nanospheres. Source data underlying $\mathbf{d}$ are provided as a Source Data file

(Supplementary Fig. 21) are set as control groups to investigate the influence of nanoparticles' surface topological structure on nano-bio interactions.

After incubating $E$. coli with the fabricated nanoparticles with different surface topologies (T-RF\&PMOs, J-RF\&PMO, RF@PMO), the SEM image clearly demonstrates that large amount of T-RF\&PMOs nanoparticles are adhered on the surface of the rod-like bacteria (Fig. 5a, Supplementary Fig. 22). The TEM image shows that the four pods of the T-RF\&PMOs nanoparticles grabbed the bacteria's surface according to the multivalent interactions, just like tribulus attach to animals' fur (Fig. 5b). In contrast, J-RF\&PMO and RF@PMO nanoparticles without the multipods structure are barely observed in the SEM and TEM images (Supplementary Fig. 23, 24), indicating that they cannot be efficiently adhered onto E. coli's surfaces. Quantitative analysis results by inductively coupled plasma (ICP) show that the adhesion amount of the multipods T-RF\&PMOs is almost fourfold comparing to the control groups (Fig. 5c), demonstrating the significance of the multipods topological structure for the enhanced nano-bio interaction. It should be noted that, the concept multivalent here is different from the multivalent that usually refers to increasing the strength of antibodies' binding towards targets with more than one binding domains according to chemical bonding. The multivalent in this article refers to the multipods nanoparticles interacting with biological hosts through the multiple pods, which is mainly based on a Van der Waals' interaction, and affected by the morphology of the nanoparticles.

Taking the advantage of the superparamagnetic $\mathrm{Fe}_{3} \mathrm{O}_{4}$ nanoparticles in the T-RF\&PMOs multipods nanocomposites, it can be used for the magnetic field induced elimination of T-RF\&PMOs adhered E. coli in water (Fig. 5d). Since a large amount of nanoparticles are adhered on E. coli's surface, the bacteria are easily separated along by the magnet under a magnetic field. The nearly transparent culture solution can be obtained after magnetic induced separation, indicating the high bacterial segregation efficiency (Supplementary Fig. 25). The elimination efficiency of the bacteria with the tetrapods structured T-RF\&PMOs nanocomposites is almost $100 \%$, which is more than three and five times higher than that of the J-RF\&PMO with Janus morphology or RF@PMO with a core@shell structure (Fig. 5e).

Many antimicrobial drugs, lysozyme for example, are insensitive toward Gram-negative strains such as E. coli, because of the protection of bacteria's outer membrane ${ }^{37,38}$. Though many efforts have been made to fabricate nanomaterials as carriers of lysozyme for increasing its antimicrobial efficiency ${ }^{39-43}$, the drug carriers often suffer from the poor bacteria adhesion ability. Herein, the T-RF\&PMOs nanoparticles with both high-surface-area mesopores for drug loading and tribulus-like tetra-pods structure for enhanced bacteria adhesion, are employed to antibacterial assessments (Supplementary Fig. 26). The surface topological structure and good dispersity of T-RF\&PMOs is maintained after lysozyme loading (Supplementary Fig. 27). The results show that the antibacterial activity of lysozyme-immobilized T-RF\&PMOs with tetra-pods topology is over $90 \%$ at the lysozyme concentration of $\sim 400 \mu \mathrm{g} \mathrm{mL}^{-1}$ (Fig. 5f). Such bacteria inhibition ability exceeds the control groups without multipods topologies. The long-term bacterial inhibition property is also evaluated to further demonstrate the antibacterial ability of lysozyme loaded tribulus-like T-RF\&PMOs nanoparticles. The lysozyme-immobilized T-RF\&PMOs nanoparticles can retain over $90 \%$ bacterial inhibition efficiency with negligible $E$. coli growth even in a long term of 3 days (Fig. 5g). In stark contrast, bacterial inhibition efficiency for the free lysozyme, lysozyme loaded J-RF\&PMO and RF@PMO nanoparticles are much lower $(<50 \%)$. The colony forming units (CFU) on agar plates of treated bacteria solution clearly show that the number of colonies in T-RF\&PMOs treated groups is significantly lower compared with the other control groups, further evidencing the multipods enhanced bacterial adhesion and inhibition ability (Supplementary Fig. 28).

\section{Discussion}

The surface-kinetics mediated multi-site nucleation strategy is proposed for the fabrication of the above mentioned mesoporous 
a

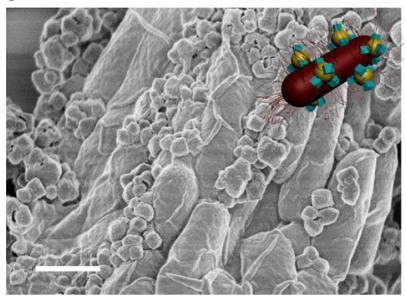

b



C

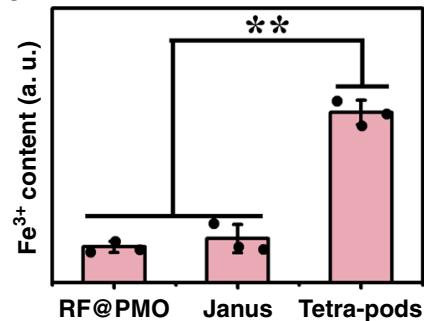

d

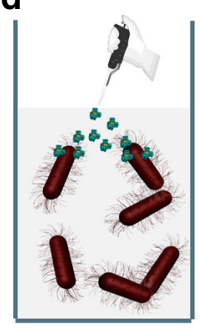

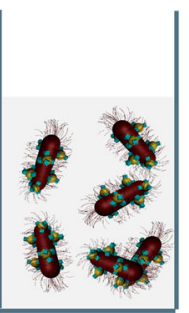

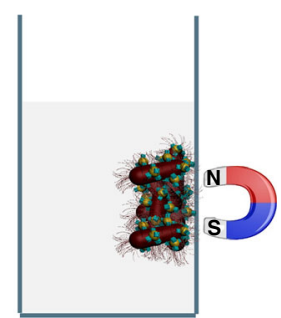

f

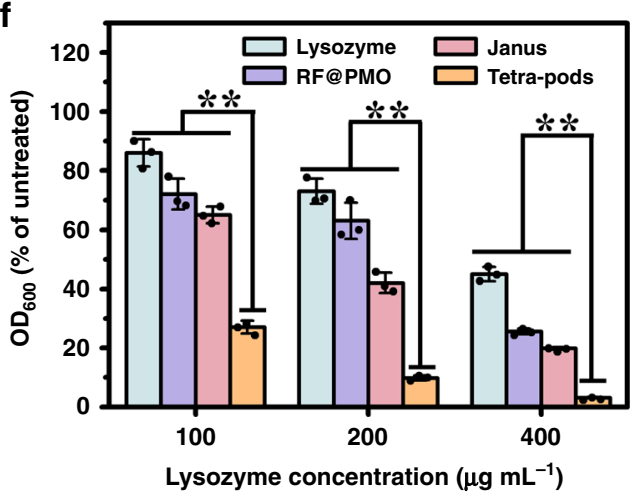

e



$\mathbf{g}$

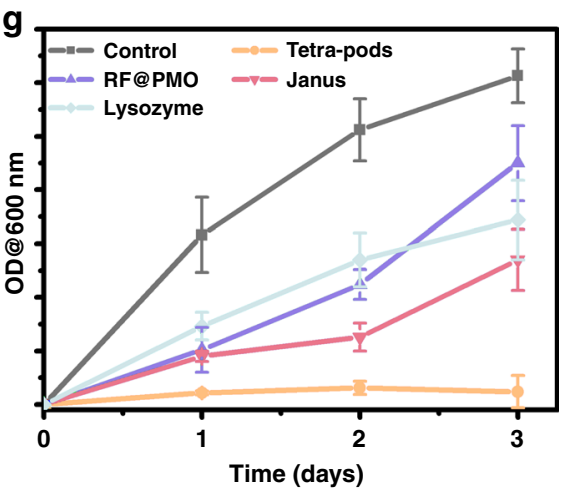

Fig. 5 Surface topologies enhanced bacterial adhesion and inhibition. a SEM, b TEM images and (inset of a) 3D structural model of the tetra-pods $\mathrm{Fe}_{3} \mathrm{O}_{4} @ \mathrm{SiO}_{2} @ \mathrm{RF} \& \mathrm{PMOs}$ nanoparticles adhered on E. coli surfaces. Scale bars represent $1 \mu \mathrm{m}$ for a, $100 \mathrm{~nm}$ for $\mathbf{b}$. c Quantitative analyses of the nanoparticles adhered on bacteria from ICP based on $\mathrm{Fe}^{3+}$ concentration: the tetra-pods $\mathrm{Fe}_{3} \mathrm{O}_{4} @ \mathrm{SiO}_{2} @ \mathrm{RF} \& \mathrm{PMOs}$ (Tetra-pods), Janus $\mathrm{Fe}_{3} \mathrm{O}_{4} @ \mathrm{SiO}_{2} @ \mathrm{RF} \& \mathrm{PMO}$ (Janus) and core@shell $\mathrm{Fe}_{3} \mathrm{O}_{4} @ \mathrm{SiO}_{2} @ R F \& P M O$ (RF@PMO) nanocomposites. d Schematic illustration of the adhesion and magnetic induced separation of $E$. coli with the multipods nanocomposites. e Quantitative analysis of $E$. coli in the PBS solution after the magnetic induced separation process. Optical density (OD) value is positive correlated with the amount of bacteria in the solution. $\mathbf{f} E$. coli inhibition efficiency of different nanoparticles loaded with the same amount of lysozyme within $24 \mathrm{~h}$. $\mathbf{g}$ The time-dependent $E$. coli inhibition evaluation of different nanocomposites loaded with the same amount of lysozyme $\left(400 \mu \mathrm{g} \mathrm{mL}{ }^{-1}\right)$. The bars represent mean \pm s.d. derived from $n=3$ groups of bacteria suspension. Source data underlying $\mathbf{c}, \mathbf{e}-\mathbf{g}$ are provided as a Source Data file. The statistical analysis was performed using one-way analysis of variance (ANOVA), followed by post hoc Tukey's method. ${ }^{\star \star} P<0.01$

multipods with precisely tunable surface topological structures (Fig. 6a). Prior to the heterogeneous nucleation on solid surface, the concentration of surfactants/silicate oligomers in the solution increases with the hydrolysis of silanes as the silica precursors (Fig. 6b), and the generation speed of the oligomers in the solution is decreased as the prolonging of hydrolysis of the silane. When the concentration of the surfactants/silicate oligomers rises to the critical nucleation concentration $\left(C_{n}\right)$, large amount of oligomers in the solution are instantly consumed for the formation of nucleation sites on the solid surface. When this consumption speed for the nucleation on solid surface is faster than the generation speed of the oligomers from silanes, it can result in decrease of the oligomer concentration in the solution. Until the oligomer amount in the solution is lower below the critical nucleation concentration $\left(C_{n}\right)$, the heterogeneous nucleation is terminated and the PMO nuclei continuously grow into larger cubic domains on solid surface. In the whole process, the duration time $\left(\Delta t_{n}\right)$ that the oligomer amount in solution is above the critical nucleation concentration is crucial for the determination of the nucleation number on solid surface. The longer the duration time of nucleation $\left(\Delta t_{n}\right)$ is, the more nucleation sites are formed. Traditionally, the reaction kinetics in the solution for the generation of oligomers is used to manipulate this duration time of nucleation $\left(\Delta t_{n}\right)^{44-46}$. Herein, the surface nucleation kinetics of oligomers on the solid surface, which determines the critical nucleation concentration $\left(C_{n}\right)$, is proposed and used for the manipulation the duration time of nucleation $\left(\Delta t_{n}\right)$.

Since oxygen anions' nucleophilicity on the surface of polymeric $\mathrm{RF}$ is stronger than that of oxygen in $\mathrm{Si}-\mathrm{OH}$ groups on $\mathrm{SiO}_{2}$ surface (Fig. 6b), the reaction activity of silane nucleophilic substitution (i.e., nucleation capability) on RF surface is higher than that on $\mathrm{SiO}_{2}$ surface, meaning that the critical nucleation concentration of surfactants/silicate oligomers on RF surface $\left(C_{1}\right)$ is lower than that on $\mathrm{SiO}_{2}$ surface $\left(C_{2}\right)$ (Fig. 6a) ${ }^{47,48}$. So, when all the experimental conditions are consistent, the starting time of the heterogeneous nucleation on the RF surface $\left(T_{1}\right)$ is earlier than that on $\mathrm{SiO}_{2}$ surface $\left(T_{2}\right)$, indicating that the generation speed of the oligomers in the solution is quicker at the relatively 
a

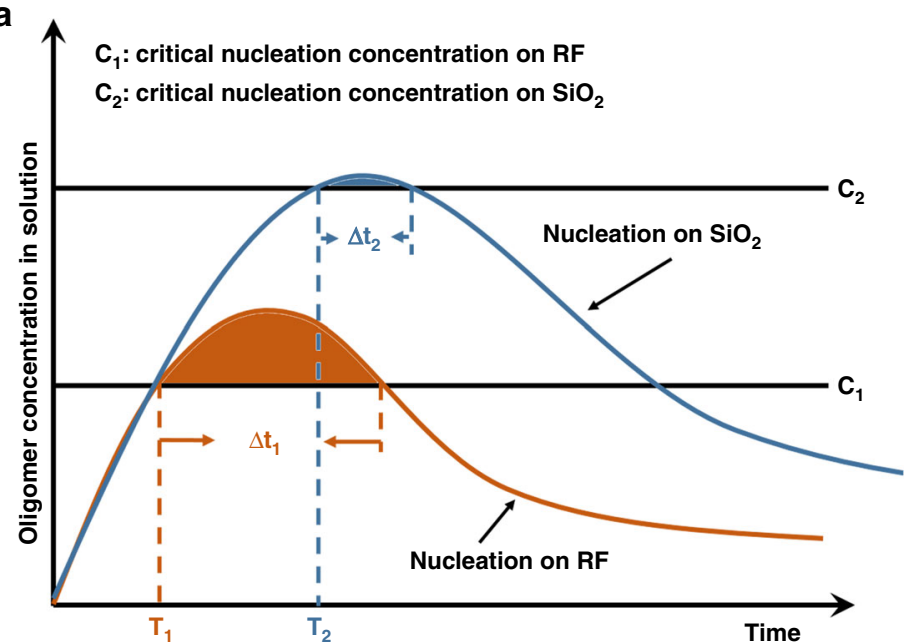

b

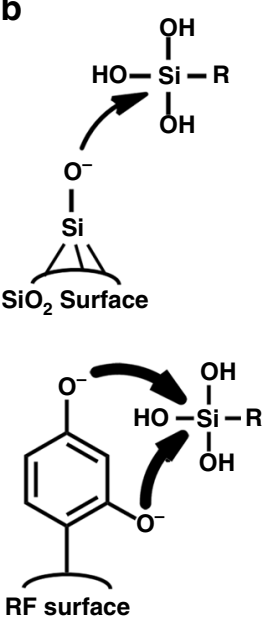

C

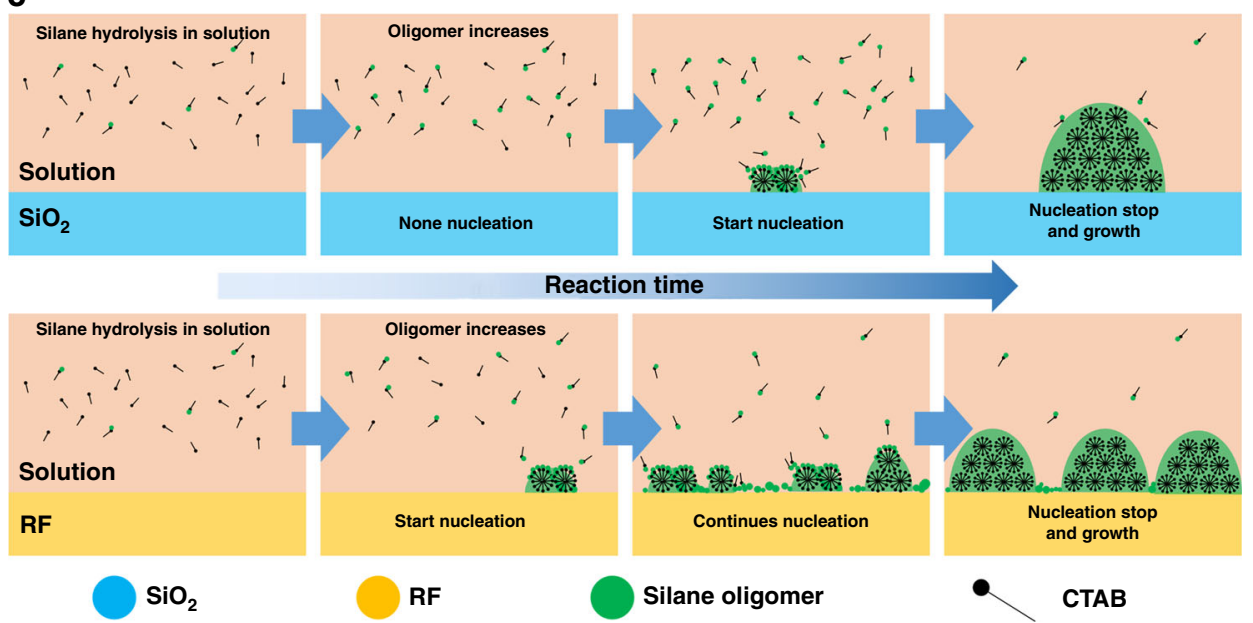

Fig. 6 The mechanism of the surface-kinetics mediated multi-site nucleation strategy. a The schematic illustration of the surfactants/silicate oligomers concentration in the solution at different reaction time with the presence of different nucleation substrates $\left(\mathrm{SiO}_{2}\right.$ and RF). $\mathrm{C}_{n}$ is the critical nucleation concentration of surfactants/silicate oligomers for the heterogeneous nucleation of PMOs on the particle surface; $T_{n}$ and $\Delta t_{n}$ are the starting and duration time of the heterogeneous nucleation on the particle surface. $\mathbf{b}$ The schematic illustration of the reaction activity of the silane nucleophilic substitution on $\mathrm{SiO}_{2}$ and $\mathrm{RF}$ surfaces (i.e., nucleation activity). Because the reaction activity of silane nucleophilic substitution on RF surface (with abundant $\mathrm{Ph}-\mathrm{OH}$ group) is higher than that on $\mathrm{SiO}_{2}$ surface (with abundant $\mathrm{Si}-\mathrm{OH}$ group), in Fig. $6 \mathrm{a}$, the critical nucleation concentration of surfactants/silicate monomer on $\mathrm{RF}$ surface $\left(\mathrm{C}_{1}\right)$ is lower than that on $\mathrm{SiO}_{2}$ surface $\left(\mathrm{C}_{2}\right)$. c Schematic illustration of the surface-kinetics mediated multi-site nucleation of surfactants/silicate oligomers on $\mathrm{SiO}_{2}$ and $\mathrm{RF}$ surface. The prolonged duration time of $\mathrm{PMO}$ nucleation on $\mathrm{RF}$ surface comparing to that of on $\mathrm{SiO}_{2}$ surface induces the continuous multiple nucleation of surfactants/ silicate oligomers on the surface of $\mathrm{Fe}_{3} \mathrm{O}_{4} @ \mathrm{SiO}_{2} @ \mathrm{RF}$ nanoparticles, and thus the multipods topological structure

earlier starting time of the nucleation on the RF surface. In comparison, the generation speed of the oligomers is slower at the relatively later starting time of the nucleation on the $\mathrm{SiO}_{2}$ surface, because the generation speed in the solution is decreased as the prolonging of hydrolysis of the silane precursors, which can be confirmed by the experimental results (Supplementary Fig. 29, 30 ). Due to the difference on the generation speed of the oligomers at their respective starting time of nucleation induced by the different surface reaction kinetics, the duration time of the nucleation on RF surface $\left(\Delta t_{1}\right)$ is longer than that on $\mathrm{SiO}_{2}$ surface $\left(\Delta t_{2}\right)$ (Fig. 6b), inducing the continuous multiple nucleation of surfactants/silicate oligomers on the RF surface and thus the multipods topological structure (Fig. 6c).

The surface kinetics of the heterogeneous nucleation of surfactants/silicate oligomers can be precisely manipulated through changing the surface functional groups of RF layers (Fig. 3). Amino is a weaker nucleophilic group compared to phenolic hydroxyl groups on RF surface, while phenolic nitro group is stronger due to strong electron-withdrawing ability of $\mathrm{NO}_{2}$ groups. Thus, the critical nucleation concentration of the surfactants/silicate monomers on RF-N surface with phenolic nitro groups is the lowest, and that on RF-A surface with phenolic amino groups is the highest among the three (Supplementary Fig. 31), resulting in differed starting and duration time of the nucleation, thus different number of nucleation sites. These inferences are consistent with the experimental results (Fig. 3). The surface kinetics of the heterogeneous nucleation of surfactants/silicate oligomers on RF can also be precisely manipulated by the surface modification with polymers (PVP, Fig. 2c). The nucleophilic ability of carbonyl group in PVP is weaker than phenolic hydroxyl groups in RF. After the surface modification with PVP, the initial phenolic hydroxyl groups in RF is covered by carbonyl groups with weaker nucleophilic ability. Therefore, the surface kinetics of RF is decreased by PVP coverage. The critical nucleation concentration of oligomers on RF-PVP surface is increased. Thus, the starting time of the heterogeneous nucleation is delayed. Duration time of nucleation is shortened and 
the multi-site nucleation of PMOs is hindered, resulting in Janus architectures.

In comparison, although the generation speed of silicate oligomers can be increased by increasing the amount of the silane precursors and the alkalinity of the solution, such increase is invalid for the heterogeneous multi-site nucleation. The high concentration of the silane oligomers in the solution induced by increasing the precursor and alkalinity of the solution, can only result in the homogeneous nucleation of the oligomers in the solution, rather than the heterogeneous nucleation on the RF surface (Supplementary Fig. 32).

This surface-kinetics mediated multi-site nucleation strategy can also be utilized to demonstrate the correlation between the number of nucleation sites and particle diameter (Fig. 4d). When the reaction condition is retained constant, the surface reaction kinetics of silane condensation on $\mathrm{Fe}_{3} \mathrm{O}_{4} @ \mathrm{SiO}_{2} @ \mathrm{RF}$ nanoparticles is fixed, as well as the number of PMOs nucleation sites per unit area. However, as the number of nucleation sites on each particle is determined by its outer surface area: the larger the nanoparticles are, the larger surface area for nucleation is, the higher the number of nucleation sites can be. So, the number of PMO pods on the surface can be precisely controlled by the diameter of $\mathrm{Fe}_{3} \mathrm{O}_{4} @$ $\mathrm{SiO}_{2} @ \mathrm{RF}$ nanoparticles. In the case of $\mathrm{Fe}_{3} \mathrm{O}_{4} @ \mathrm{mRF}$ nanoparticles (Fig. 4e-h), mesopores endow the RF surface with higher surface area, and thus higher PMO nucleation site number as well.

In summary, the surface-kinetics mediated multi-site nucleation strategy is developed for the fabrication of a family of uniform mesoporous multipods $\mathrm{Fe}_{3} \mathrm{O}_{4} @ \mathrm{SiO}_{2} @ \mathrm{RF} \& \mathrm{PMO}$ nanocomposites with controllable surface topologies. The mesoporous multipods structures contain one core@shell $\mathrm{Fe}_{3} \mathrm{O}_{4} @ \mathrm{SiO}_{2} @ \mathrm{RF}$ nanosphere as a center and controllable number of multiple PMO cubes circling the sphere as pods. The number of nucleation sites can be precisely controlled from one (Janus nanostructure) to four (tetrapods nanostructure) by mediation of the surface properties of RF. Due to the multipods structure enhanced nano-bio interaction, the tribulus-like tetra-pods mesoporous nanocomposites possess high bacteria adhesion capacity and perform nearly $100 \%$ bacterial segregation as well as long-term inhibition over $90 \%$. We consider that the developed surface-kinetics mediated multi-site nucleation strategy provides a pathway in the rational design of functional mesoporous nanoparticles with controllable surface topological structures for enhanced nano-bio interactions.

\footnotetext{
Methods

Synthesis of $\mathrm{Fe}_{3} \mathbf{O}_{4}$ nanoparticles. Magnetic $\mathrm{Fe}_{3} \mathrm{O}_{4}$ nanoparticles with an average diameter of $120 \mathrm{~nm}$ were synthesized as following ${ }^{49}$. $\mathrm{FeCl}_{3} \cdot 6 \mathrm{H}_{2} \mathrm{O}(3.25 \mathrm{~g}, 20 \mathrm{mmol})$, ethylene glycol $(100 \mathrm{~mL})$, trisodium citrate $(1.30 \mathrm{~g}, 4.4 \mathrm{mmol})$ and $\mathrm{NaAc}(6.00 \mathrm{~g}, 44$ $\mathrm{mmol}$ ) were mixed and sonicated for $1 \mathrm{~h}$. The mixture was then transferred into a 200 -mL Teflon-lined stainless-steel autoclave. The autoclave was heated at $200^{\circ} \mathrm{C}$ for $10 \mathrm{~h}$. After cooling down to room temperature, the products were washed with distilled water and ethanol and finally dispersed in ethanol for further usages.
}

Synthesis of core@shell $\mathbf{F e}_{\mathbf{3}} \mathbf{O}_{\mathbf{4}} @ \mathrm{SiO}_{\mathbf{2}}$ nanoparticles. Core@shell structured $\mathrm{Fe}_{3} \mathrm{O}_{4} @ \mathrm{SiO}_{2}$ nanoparticles with a diameter of $180 \mathrm{~nm}$ were synthesized as following ${ }^{50}$. Typically, $40 \mathrm{mg}$ of the $\mathrm{Fe}_{3} \mathrm{O}_{4}$ nanoparticles obtained above were dispersed in the mixture of ethanol $(35 \mathrm{~mL})$ and $\mathrm{H}_{2} \mathrm{O}(8.75 \mathrm{~mL})$. Then, ammonium hydroxide $(25 \mathrm{wt} \%, 0.75 \mathrm{~mL})$ was added with stirring. TEOS $(75 \mu \mathrm{L})$ was then added dropwise. The mixture was stirred for $12 \mathrm{~h}$ at room temperature, then centrifuged and washed with water and ethanol. Finally, the core@shell $\mathrm{Fe}_{3} \mathrm{O}_{4} @$ $\mathrm{SiO}_{2}$ nanoparticles with a diameter of $180 \mathrm{~nm}$ were obtained. For the synthesis of the $\mathrm{Fe}_{3} \mathrm{O}_{4} @ \mathrm{SiO}_{2}$ nanoparticles with a diameter of $250 \mathrm{~nm}$, the amount of TEOS was increased to $200 \mu \mathrm{L}$ and the other conditions were retained unchanged.

Synthesis of $\mathbf{F e}_{\mathbf{3}} \mathbf{O}_{\mathbf{4}} @ \mathrm{SiO}_{\mathbf{2}} @ \mathbf{R F}$ nanoparticles. The coating of RF layers on the core@shell $\mathrm{Fe}_{3} \mathrm{O}_{4} @ \mathrm{SiO}_{2}$ nanoparticles to form $\mathrm{Fe}_{3} \mathrm{O}_{4} @ \mathrm{SiO}_{2} @ \mathrm{RF}$ core@shell@shell nanospheres with a diameter of $\sim 260 \mathrm{~nm}$ was realized through an extended Stöber method ${ }^{44}$. In a typical synthesis, $60 \mathrm{mg}$ of the core@shell structured $\mathrm{Fe}_{3} \mathrm{O}_{4} @ \mathrm{SiO}_{2}$ nanoparticles was dispersed in a mixture of $\mathrm{H}_{2} \mathrm{O}(120 \mathrm{~mL})$, ethanol $(240 \mathrm{~mL})$, resorcinol $(500 \mathrm{mg}, 4.5 \mathrm{mmol})$ and formaldehyde $(500 \mu \mathrm{L}, 16.7 \mathrm{mmol}) .6 .0 \mathrm{~mL}$ of ammonium hydroxide $(25 \mathrm{wt} \%$ ) was added dropwise to initialize the reaction. The mixture was stirred for $5 \mathrm{~h}$ at room temperature, then the product was centrifuged and washed with water and ethanol. For the preparation of $\mathrm{Fe}_{3} \mathrm{O}_{4} @ \mathrm{SiO}_{2} @ \mathrm{RF}$ nanoparticles with a diameter of $160,200,230 \mathrm{~nm}$, the reaction time was shortened from 5 to $1.5,3,4 \mathrm{~h}$, respectively.

Synthesis of tetra-pods $\mathrm{Fe}_{3} \mathbf{O}_{\mathbf{4}} @ \mathrm{SiO}_{\mathbf{2}} @ \mathrm{RF} \& \mathrm{PMOs}$ nanoparticles. The multi-site nucleation of highly ordered PMOs on the core@shell structured $\mathrm{Fe}_{3} \mathrm{O}_{4} @ \mathrm{SiO}_{2} @ \mathrm{RF}$ nanoparticles was carried out through the surface-kinetics mediated multi-site nucleation strategy. In a typical synthesis, $10 \mathrm{mg}$ of the above $\mathrm{Fe}_{3} \mathrm{O}_{4} @ \mathrm{SiO}_{2} @ \mathrm{RF}$ nanoparticles with a diameter of $\sim 260 \mathrm{~nm}$ was dispersed in $38 \mathrm{~mL}$ of $\mathrm{H}_{2} \mathrm{O}$ and $2.0 \mathrm{~mL}$ of ethanol. In total $150 \mathrm{mg}$ of cetyltrimethyl ammonium bromide (CTAB) and $1.8 \mathrm{~mL}$ of ammonium hydroxide $(25 \mathrm{wt} \%)$ were added in succession. The mixture was stirred for $30 \mathrm{~min}$, then $50 \mu \mathrm{L}$ of bis(triethoxysilyl)ethane (BTEE) was added dropwise with stirring for another $3 \mathrm{~h}$. The product was centrifuged and washed with water and ethanol.

Bacteria adhesion. E. coli (American type culture collection No. 12435) was first cultured in Luria-Bertani (LB) liquid medium (tryptone $10 \mathrm{~g} \mathrm{~L}^{-1}$, yeast extract $5.0 \mathrm{~g} \mathrm{~L}^{-1}, \mathrm{NaCl} 10 \mathrm{~g} \mathrm{~L}^{-1}, \mathrm{pH} 7.0$ ) at $37^{\circ} \mathrm{C}$ under shaking at $200 \mathrm{rpm}$ for $12 \mathrm{~h}$. After diluting the bacterial suspension with Luria-Bertani (LB) medium, the nanoparticles dispersed in phosphate buffer saline (PBS) solution $\left(1.0 \mathrm{mg} \mathrm{mL}^{-1}\right)$ were added. The mixture was further incubated in $37^{\circ} \mathrm{C}$ for $24 \mathrm{~h}$. The samples were then fixed and stained with $2.5 \%$ glutaraldehyde. A drop of bacteria suspension was dropped and dried on the cupper grid for TEM characterization. The dried samples were sputter-coated with gold for SEM imaging. More than 10 positions were randomly selected to take the electron microscope images. The quantitative analyses of the nanoparticles adhered on bacteria were determined by inductively coupled plasma (ICP) based on $\mathrm{Fe}^{3+}$ concentration.

Reporting Summary. Further information on research design is available in the Nature Research Reporting Summary linked to this article.

\section{Data availability}

Data supporting the findings of this study are available within the article and the associated Supplementary Information Section. Any other data are available from the corresponding authors upon reasonable request. The source data underlying Figs. $4 \mathrm{~d}, 5 \mathrm{c}$, 5e-5g and Supplementary Figs. 4, 8, 16 and 26 are provided as a Source Data file.

Received: 3 June 2019; Accepted: 6 September 2019;

Published online: 26 September 2019

\section{References}

1. Liu, Y., He, K., Chen, G., Leow, W. \& Chen, X. Nature-inspired structural materials for flexible electronic devices. Chem. Rev. 117, 12893-12941 (2017).

2. Huang, J. et al. Bio-inspired synthesis of metal nanomaterials and applications. Chem. Soc. Rev. 44, 6330-6374 (2015).

3. Wang, Z. et al. Biomimetic nanoflowers by self-assembly of nanozymes to induce intracellular oxidative damage against hypoxic tumors. Nat. Commun. 9, 3334 (2018).

4. Xia, F. \& Jiang, L. Bio-inspired, smart, multiscale interfacial materials. Adv. Mater. 20, 2842-2858 (2008).

5. Liu, N. et al. A pomegranate-inspired nanoscale design for large-volumechange lithium battery anodes. Nat. Nanotechnol. 9, 187-192 (2014).

6. Nathan, R. et al. Mechanisms of long-distance seed dispersal. Trends Ecol. Evol. 23, 638-647 (2008).

7. Taylor, N. M. et al. Structure of the T4 baseplate and its function in triggering sheath contraction. Nature 533, 346-352 (2016).

8. Canton, I. \& Battaglia, G. Endocytosis at the nanoscale. Chem. Soc. Rev. 41, 2718-2739 (2012)

9. Zhu, P. et al. Distribution and three-dimensional structure of AIDS virus envelope spikes. Nature 441, 847-852 (2006).

10. Fasting, C. et al. Multivalency as a chemical organization and action principle Angew. Chem. Int. Ed. 51, 10472-10498 (2012).

11. $\mathrm{Hu}, \mathrm{X}$. et al. Polyprodrug amphiphiles: hierarchical assemblies for shaperegulated cellular internalization, trafficking, and drug delivery. J. Am. Chem. Soc. 135, 17617-17629 (2013)

12. Dai, Y., Xu, C., Sun, X. \& Chen, X. Nanoparticle design strategies for enhanced anticancer therapy by exploiting the tumour microenvironment. Chem. Soc. Rev. 46, 3830-3852 (2017).

13. Nel, A. et al. Understanding biophysicochemical interactions at the nano-bio interface. Nat. Mater. 8, 543 (2009).

14. Blanco, E., Shen, H. \& Ferrari, M. Principles of nanoparticle design for overcoming biological barriers to drug delivery. Nat. Biotechnol. 33, 941-951 (2015). 
15. Hinde, E. et al. Pair correlation microscopy reveals the role of nanoparticle shape in intracellular transport and site of drug release. Nat. Nanotechnol. 12, 81-89 (2017).

16. Niu, Y. et al. Nanoparticles mimicking viral surface topography for enhanced cellular delivery. Adv. Mater. 25, 6233-6237 (2013).

17. Wang, W. et al. Facile synthesis of uniform virus-like mesoporous silica nanoparticles for enhanced cellular internalization. ACS Cent. Sci. 3, 839-846 (2017).

18. Wang, J. et al. Physical activation of innate immunity by spiky particles. Nat. Nanotechnol. 13, 1078-1086 (2018).

19. Ye, E., Regulacio, M. D., Zhang, S. Y., Loh, X. J. \& Han, M. Y. Anisotropically branched metal nanostructures. Chem. Soc. Rev. 44, 6001-6017 (2015).

20. Regulacio, M. D. \& Han, M. Y. Multinary I-III-VI2 and I2-II-IV-VI4 semiconductor nanostructures for photocatalytic applications. Acc. Chem. Res. 49, 511-519 (2016)

21. Manna, L., Milliron, D., Meisel, A., Scher, E. \& Alivisatos, A. Controlled growth of tetrapod-branched inorganic nanocrystals. Nat. Mater. 2, 382-385 (2003).

22. Mokari, T., Rothenberg, E., Popov, I., Costi, R. \& Banin, U. Selective growth of metal tips onto semiconductor quantum rods and tetrapods. Science 304, 1787-1790 (2004).

23. Wu, X. J. et al. Controlled growth of high-density CdS and CdSe nanorod arrays on selective facets of two-dimensional semiconductor nanoplates. Nat. Chem. 8, 470-475 (2016).

24. Bahng, J. H. et al. Anomalous dispersions of 'hedgehog' particles. Nature 517, 596-599 (2015).

25. Liu, Y. et al. Designable yolk-shell nanoparticle@mof petalous heterostructures. Chem. Mater. 26, 1119-1125 (2014)

26. Suteewong, T. et al. Multicompartment mesoporous silica nanoparticles with branched shapes: an epitaxial growth mechanism. Science 340, 337-341 (2013).

27. Croissant, J. et al. One-pot construction of multipodal hybrid periodic mesoporous organosilica nanoparticles with crystal-like architectures. Adv. Mater. 27, 145-149 (2015)

28. $\mathrm{Li}, \mathrm{X}$. et al. Anisotropic growth-induced synthesis of dual-compartment Janus mesoporous silica nanoparticles for bimodal triggered drugs delivery. J. Am. Chem. Soc. 136, 15086-15092 (2014).

29. Yang, T. et al. Dumbbell-shaped bi-component mesoporous janus solid nanoparticles for biphasic interface catalysis. Angew. Chem. Int. Ed. 56, 8459-8463 (2017).

30. Zhao, T. et al. Spatial isolation of carbon and silica in a single janus mesoporous nanoparticle with tunable amphiphilicity. J. Am. Chem. Soc. 140, 10009-10015 (2018).

31. Li, X. et al. Anisotropic encapsulation-induced synthesis of asymmetric singlehole mesoporous nanocages. J. Am. Chem. Soc. 137, 5903-5906 (2015).

32. $\mathrm{Li}, \mathrm{X}$. et al. Degradation-restructuring induced anisotropic epitaxial growth for fabrication of asymmetric diblock and triblock mesoporous nanocomposites. Adv. Mater. 29, 1701652 (2017).

33. Fischbach, M. \& Walsh, C. Antibiotics for emerging pathogens. Science 325 , 1089-1093 (2009).

34. Lewis, K. Platforms for antibiotic discovery. Nat. Rev. Drug Discov. 12, 371-387 (2013).

35. Schloissnig, S. et al. Genomic variation landscape of the human gut microbiome. Nature 493, 45-50 (2013).

36. Tenaillon, O., Skurnik, D., Picard, B. \& Denamur, E. The population genetics of commensal Escherichia coli. Nat. Rev. Microbiol. 8, 207-217 (2010).

37. Chipman, D. \& Sharon, N. Mechanism of lysozyme action. Science 165, 454-465 (1969).

38. Payne, C. et al. Fungal cellulases. Chem. Rev. 115, 1308-1448 (2015).

39. $\mathrm{Mu}, \mathrm{Q}$. et al. Chemical basis of interactions between engineered nanoparticles and biological systems. Chem. Rev. 114, 7740-7781 (2014).

40. Tripathy, N., Ahmad, R., Bang, S., Min, J. \& Hahn, Y. Tailored lysozyme-ZnO nanoparticle conjugates as nanoantibiotics. Chem. Commun. 50, 9298-9301 (2014).

41. Wang, Y. et al. Small-sized and large-pore dendritic mesoporous silica nanoparticles enhance antimicrobial enzyme delivery. J. Mater. Chem. B 4, 2646-2653 (2016).

42. Vertegel, A., Siegel, R. \& Dordick, J. Silica nanoparticle size influences the structure and enzymatic activity of adsorbed lysozyme. Langmuir 20, 6800-6807 (2004).

43. Luckarift, H., Dickerson, M., Sandhage, K. \& Spain, J. Rapid, roomtemperature synthesis of antibacterial bionanocomposites of lysozyme with amorphous silica or titania. Small 2, 640-643 (2006).
44. Wong, Y. et al. Revisiting the Stöber method: inhomogeneity in silica shells. J. Am. Chem. Soc. 133, 11422-11425 (2011).

45. Wang, G. et al. Island growth in the seed-mediated overgrowth of monometallic colloidal nanostructures. Chemistry 3, 678-690 (2017).

46. $\mathrm{Li}, \mathrm{W}$. et al. A versatile kinetics-controlled coating method to construct uniform porous $\mathrm{TiO}_{2}$ shells for multifunctional core-shell structures. J. Am. Chem. Soc. 134, 11864-11867 (2012).

47. Liu, J. et al. Extension of the Stöber method to the preparation of monodisperse resorcinol-formaldehyde resin polymer and carbon spheres. Angew. Chem. Int. Ed. 123, 6069-6073 (2011).

48. Liu, J. et al. A facile soft-template synthesis of mesoporous polymeric and carbonaceous nanospheres. Nat. Commun. 4, 2798 (2013).

49. Liu, J. et al. Highly water-dispersible biocompatible magnetite particles with low cytotoxicity stabilized by citrate groups. Angew. Chem. Int. Ed. 48, 5875-5879 (2009)

50. Deng, Y., Qi, D., Deng, C., Zhang, X. \& Zhao, D. Y. Superparamagnetic highmagnetization microspheres with a $\mathrm{Fe}_{3} \mathrm{O}_{4} @ \mathrm{SiO}_{2}$ core and perpendicularly aligned mesoporous $\mathrm{SiO}_{2}$ shell for removal of microcystins. J. Am. Chem. Soc. 130, 28-29 (2008).

\section{Acknowledgements}

The work was supported by the National Key R\&D Program of China (2017YFA0207303, 2018YFA0209400), Key Basic Research Program of Science and Technology Commission of Shanghai Municipality (17JC1400100), National Natural Science Foundation of China $(21875043,21733003,21701027)$, Natural Science Foundation of Shanghai (18ZR1404600), and Shanghai Sailing Program (17YF1401000). This work was funded by the Deanship of Scientific Research at Princess Nourah Bint Abdulrahman University, through the Research Groups Program Grant No. RGP-14380006 .

\section{Author contributions}

D.Z., X.L., and T.Z. contributed to the conception and design of the experiments, analysis of the data and writing the manuscript. L.C., P.W., B.L., R.L., F.Z., and X.L. assisted T.Z for the synthesis of materials and the data collection and analysis, A.A.K. and W.N.H. involved in partial bacteria data and analysis. All authors contributed to the discussion and manuscript preparation.

\section{Competing interests}

The authors declare no competing interests.

\section{Additional information}

Supplementary information is available for this paper at https://doi.org/10.1038/s41467 019-12378-0.

Correspondence and requests for materials should be addressed to X.L. or D.Z.

Peer review information Nature Communications thanks An-Hui Lu and the other, anonymous, reviewer(s) for their contribution to the peer review of this work. Peer reviewer reports are available.

Reprints and permission information is available at http://www.nature.com/reprints

Publisher's note Springer Nature remains neutral with regard to jurisdictional claims in published maps and institutional affiliations.

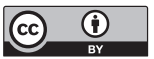

Open Access This article is licensed under a Creative Commons Attribution 4.0 International License, which permits use, sharing, adaptation, distribution and reproduction in any medium or format, as long as you give appropriate credit to the original author(s) and the source, provide a link to the Creative Commons license, and indicate if changes were made. The images or other third party material in this article are included in the article's Creative Commons license, unless indicated otherwise in a credit line to the material. If material is not included in the article's Creative Commons license and your intended use is not permitted by statutory regulation or exceeds the permitted use, you will need to obtain permission directly from the copyright holder. To view a copy of this license, visit http://creativecommons.org/ licenses/by/4.0/.

(C) The Author(s) 2019 